\title{
Study on the Self-development of "Metalworking Practice" Course
}

\author{
Jianchao Zhang ${ }^{\mathrm{a}}$, Wenjiang $\mathrm{Wu}^{\mathrm{b}}$, Zhanfeng $\mathrm{Gao}^{\mathrm{c}}$, \\ Beibei Chu ${ }^{\mathrm{d}}$ and Yaoyuan Wei ${ }^{\mathrm{e}}$
}

\author{
Engineering Training Center, Shijiazhuang Tiedao University, Shijiazhuang 050043, China \\ azhangjianchao@yeah.net, bbfwwj@163.com, cgaozhanfeng88@126.com, \\ d25563076@qq.com, ewyy@stdu.edu.cn
}

Keywords: Metalworking practice, practice, innovation, development.

\begin{abstract}
Currently, metalworking practice is no longer being treated as the only practice course on metallurgical technology in universities; multi-development and a variety of extension on this practice course are made. However some problems still existed and need to be solved. Hence we should encourage students to form macroscopic concept on industrial production in their mind during their "metalworking practice" and constantly improve actual environment of practice site. We should lay the emphasis on the hands-on practice as well as on ability innovation, establish the safety guarantee system and improve the assessment system on students' performance. We should communicate with students on various aspects and adjust the arrangements on projects of supply sides. Based on the "metalworking practice" concept we should arrange well the related follow-up courses after metalworking practice and expand the brand new practice course to adapt with the practice needs from other majors. We should give full play of "metalworking practice" and train the hands-on ability and innovation ability of students from other majors.
\end{abstract}

\section{Introduction}

"Metalworking practice" is short for "Metal processing technology practice". As the development on science and change of time, more and more colleges and universities are no longer treating metalworking practice as the only practice course on metallurgical technology but are making multi-development and a variety of extension on this practice course [1,2]. Besides the choiceness and sublimation on the traditional training, "new technology, new equipment and new processing method" are being included in the practice course. A breakthrough is made on traditional metalworking practice which dedicated for single type of work and single technique; a comprehensive and innovative training requirement is given. After the real teaching practice, a preliminary and good training result is achieved. However a number of problems still exist during the reform and development of metalworking practice and those issues need to be solved urgently.

\section{Current teaching situation on metalworking practice}

The basic requirements on metalworking practice include: complete learning on operation of machining, clamping, welding, casting and NC machining as well as on the basic knowledge of metalwork. Students should know the process of machining and be familiar with the common processing on mechanical components, basic principle on structure of the equipment and operation of tool, fixture and gauge and finally they should be able to machine simple components independently; Through the practice on machining simple components, students will consolidate and deepen their knowledge on mechanical drawing and the application, thus their ability on analyzing processing technology will be enhanced; Students will get trained on having right attitude towards labor; and work style, the economic view of linking theory with practice will be enhanced in students' minds 
Currently in most universities, the old-fashioned concept of laying emphasis on practice and neglecting of engineering quality training is under changing. The expense on metalworking practice is increased year by year. The backward situations such as out-of-date equipment in metalworking practice, inadequate practice activities etc. are preliminarily get changed. They are constantly making innovation on traditional teaching method in an aim to train students with practical technique and creative minds. Based on the problems which existed in traditional metalworking practice teaching, Gao Qi and several other people have presented the innovative multi-layered "metalworking training" plan of unitary organization on type of work, menu type of option in an aim to improve the training on the engineering ability of students[3]. Based on this traditional practice, Gong Yuan and several other people have presented the course system featured with "type of work + Layer" and improve the quality monitoring system and performance assessment system in an aim to lead metalworking practice to a healthy development [4]. Li Junxia and several other people have presented the second phase of teaching model on metalworking practice and have already put into practice with good result [5]. Duan Chengyan and several other people raised the idea of bringing the core thinking of CDIC engineering education into the whole practice of metalworking by combining "Excellent engineers training plan” [6]. Based on current teaching situation on metalworking practice, Su Huanhuan has constantly made reform on aspects such as courses construction and teaching model etc. by applying the TRIZ innovative theory, some innovation has been made on teaching content, teaching method and teaching means etc. The innovative practical teaching model is being created [7].

However as different university has different self-development situation and different training target; at the same time, they are constrained by shortage on practice expenses and shortage on technicians, and also they are inadequate in terms of management knowledge. There is no standard reform template on metalworking practice which is suitable for everywhere. In this article, based on over 10 years of experiment of the writer together with the team on the reform of metalworking practice teaching as well as on establishment of engineering training center, we will briefly study the unsettled problems which lies in the self-development of "metalworking practice" and give the introduction on the development and construction of practice courses based on metalworking practice.

\section{Problems which need to be solved in the self-development of metalworking practice}

1) Macroscopic concept on industrial production should be formed in students' mind.

In the old learning system, metalworking practice is the basic training course in terms of metallurgical technology profession. In most of colleges and universities, metalworking practice course is usually arranged in freshman year or sophomore year. Although during this phase, practice courses are fully prepared for students, and students are usually actively participated in the course. However due to the inadequate professional knowledge students have, and especially large number of students participated in the practice, practice time arranged for them is limited. Under the situation usually students be arranged in groups, they shift among different type of operations, the inner connection between diffident types of operation had to be disconnected by them, this also leads to the difficult understanding by students on the role and the function of different types of work operation in industrial production, Macroscopic concept on industrial production is hard to be setup in students' mind.

Hence the introduction courses need to be setup for metalworking practice. During this time, not only the basic theoretical knowledge should be given to students, but also a typical product which integrated various of types of work in metalworking practice should be taken as an example to illustrate to students the interconnection between various of types of work; And at the same time, during teaching one type of work, we require teacher to teach to students the knowledge and operation for a certain type of work, but also let students understand the interconnection between types of work; During the practice report making phase, we require students to understand the blood ties between 
different types of work, in this way they could fully understand the cause and effect of industrial product and a comprehensive and macroscopic understanding on industrial production is achieved.

2) Hands-on practice and ability innovation should be improved in project

In recent 10 years, in most of colleges and universities, students are encouraged to make innovation in their metalworking practice; the aim of training students with innovation ability is thus achieved. I believe those ideas are necessary to be promoted. However due to inadequate professional knowledge of students and adding that the practice time arranged for them is limited, the innovation ability they could achieve during metalworking practice is limited as well. After all, "the root of innovation lies in practice".

During arrangement of projects, we should follow the principle of putting more emphasis on hands-on practice and at same at carrying out the innovation. We should take practice as main job and then being supported by innovation. We should not make the primary and the secondary upside down, i.e. emphasizing on "innovation" but neglecting "practice" training. For example, after practice course for the type of work, we could deliberately leave some time for students to make some innovation based on the learnt technique on this type of work. Hence, students get improved on hands-on ability; and interests on innovation are aroused through participation in innovation activities.

3) Improve the construction of real metalworking practice site

In some colleges and universities where hardware facilities are relatively poor and practice expenses is relatively less. Simulation software is often used by school to demonstrate to students the process of machining, milling, NC center and also to make the relative training to students. By watching the video on introduction of new material, new process and new technology from abroad, the knowledge on advanced manufacturing equipment, production process and method are learnt by students and this greatly broadened the vision and knowledge of students.

Indeed, as to some projects which are confined by actual difficult condition and within a short period of time practice is unreachable, there are certain benefits by utilizing the above methods. However, the management staff in charge of metalworking practice should strictly limit the application scale on simulation software and on video playing, prevent students from excessive reliance on those methods and giving bad influence on students' emotion in regard of practice. Because simulation product is hard to compete with machined product in terms of visual appearance, structural function and physical performance etc. and especially, as for simulation application, video playing, they are class models which are still accustomed by students, they could hardly bring to students with firsthand taste as they could personally experience on real production site. It is of great significant to improve the construction of real metalworking practice site. We need colleges and universities to expand investment and guarantee the quantity and quality of types of work which needs practice. At the same time, we should strengthen building of the training on teachers and improve the professional level of the guidance teachers.

4) Establishing safety guarantee system for metalworking practice

Since beginning of the century, a number of engineering training centers are being setup among engineering or comprehensive colleges and universities in our country. The target is letting students to complete the practice lessons such as metalworking practice etc. while in school. By considering the safety needs in enterprises, we should prevent the embarrassing situation of careless and impractical operation especially under heavy production task phase. However for students accustomed with class teaching, they may feel uncomfortable during hand-on practice in engineering training center because of the electrification, high-temperature and splashing of iron chip. So how to let students complete metalworking practice successfully is becoming a question which needs to be considered by organizer and guidance teacher. Hence, it is of great importance to establish a comprehensive and effective safety guarantee system. First we should especially emphasize the safety to students during introduction lesson on practice so as to establish the safety concept in students' minds. I have ever raised a slogan of "safety goes before study" which seems not very appropriate, but it concisely alerts the students of the importance of practice safety. Also, we should strengthen the appropriate usage on 
working clothes and labor protection devices, and should make safety operation procedures. Guidance teachers of each type of work should give lessons to students on those regulations and make relative requirements for students to follow. We should also work out measures on network monitoring and strictly monitor the practice process of students and guarantee practicably the completion of practice task by students.

5) Establish and improve metalworking practice performance assessment system

We should establish a strict student practice performance assessment system and let students understand the importance of metalworking practice course in thoughts and action. The carrier of performance assessment system of our center is called "metalworking practice card" on which information like students' name, students' no., class no., major and contact information etc. are written on it. Grading column on each type of work participated by students are also included.

The practice guidance teacher will evaluate the achievement product of students after their practice, they also take "innovation production”, "practice discipline”, "equipment maintenance”, "safety protection”, “ environmental hygiene” etc. as the assessment standards for the type of work. Once the assessment is done, they make seal as confirmation. If students could make some innovation or make some innovative products, higher score may be given. In the final score, theoretical score takes up by $20 \%$ while practice score takes up by $80 \%$. In practice score, the assessment is made based on the weight of each type of work takes up the time of the whole practice time. The assessment will be made under just and open principle and let students to be convinced.

6) Communication well with students and get to know the needs.

We should get to know the true feeling from students on the metalworking practice we arranged for them. Because although the supply side thinks that they have provided the metalworking practice courses which are complete, advanced and innovative, however for acceptance party- students, may not agree and accept with the course. Because students of modern time have their own particular understandings on training of hands-on ability and innovation during study in universities which are quite different with courses supply side.

During and after each metalworking practice and through various means like setting a suggestion box, running a forum, making assessment on practice reports, logging in metalworking post bar, and through Wechat platform etc., we absorb the new idea, new feeling, new appraisal, new suggestion, new needs from students. Thus we can make timely adjustment to the arrangements on projects and timing on metalworking practice and at the same time provide reference for other courses on hands-on ability training.

\section{Metalworking practice course linking and development}

1) The front and back linking on metalworking practice course should be arranged well.

Metalworking practice course has close relation with other courses; it serves as a link between past and future. For example, as to students majored in mechanics, metalworking practice is not only a practice course on metallurgical technology but also it has close ties with the courses of $<$ Mechanical Drawing $>$, < Electrical and Electronic Technology $>$ previous taken and courses of $<$ Interchangeability and Technical Measurement $>$, $<$ Mechanical Design $>$ and $<$ Courses Design $>$ opened later.

However, in most colleges and universities, the metalworking practice is still in a stage of basic cognitive stage. Students could not connect metalworking practice with the above courses closely; let alone the knowledge integration between different professions and subjects. Although the subtle function of metalworking practice is existed, the hidden correlation inside should be pointed out by teacher or students have to comprehend it themselves in the later stage of study hence it's hard for them to linking theory with practice independently. The students are not likely to participate in practice and have little interests in understanding the professional knowledge. Based on the above analysis, it is necessary that metalworking practice guidance teacher should not only give lessons on the knowledge and technique on the type of work which needs to be practiced, but also they should get 
to know the courses arrangement and course content for students who are from various professions and participating in various types of work practice, in this way, function of "metalworking practice" can be fully given. At the same time, the professional teachers of the courses subsequent should know the content of metalworking practice as well, so that during the lecture on professional knowledge, they can remind the students the close ties between this lecture and future metalworking practice. They could also set the practice base in an open style, letting students have the chance to practice after the lecture.

2) Opening a brand new training course to adapt with the needs of other professions on practice

As a famous brand, for a long time, metalworking practice is a necessary step for training the hands-on ability of students in mechanic major or similar major. It is even listed as the compulsory courses for other major or all majors in some colleges and universities. It is true that metalworking practice has played a very important role in training the hands-on ability of students and improving their labor awareness. However due to the time given on metalworking practice is limited and the big number of projects arranged, as for students of other profession or students lacking of free time, they should analysis the arrangement of courses and the time needed for each type of work and carefully choose the corresponding practice based on their real needs.

Based on courses of metalworking practice of our school, we run a course called "Competence training on engineering practice” [8] and this practice lasts for one week. This course is especially arranged for students who are not assigned with metalworking practice. We dedicated in training their hands-on ability. There are three models in this practical training: (1) expanding the knowledge structure: it includes practical training models like industry introduction, knowledge on railway, traditional manufacturing technology, digital control manufacturing technology, non-traditional machining technology, heat treatment technics and casting techniques etc.; (2) Practicing on hand-on ability, it includes practical training models like electromechanical assembly and disassembly, techniques of bench worker, welding of steel structure, electric safety, fundamental of electronic process etc.; (3) Training on innovation: it includes the practical training models like creative production, making of electronic product, electromechanical combination, robot technology etc. Through practical training, students get to know the development of modern manufacturing industry and railway industry; the direct and perceptual knowledge on manufacturing equipment, railway engineering and railway construction equipment are gained.

Through hands-on practice, students get acquainted with the common tools or instruments which are usually seen or used in future study or working; their hands-on ability is improved and innovation mind is fostered. Through eight years of teaching practice, better result is achieved.

3) Training students with innovative ability in multi-channel manner and from all sides

Series of competitions on innovative products were organized by Ministry of Education and other departments in recent years. In analyzing the development trend of those innovative products, we found that not only the completion of innovative design by students are required, but also according to the requirements, the final product or model should be made by students. From those practices we get to know that after metalworking practice or competence training on engineering practice, students could not only grasp the knowledge of the book which are hard to comprehend but also they learnt how to operate the machine or equipment. More importantly, they gained confidence on their ability.

In order to further develop the innovative ability of students, we should carry out innovative training in multi-channel manner and from all sides. The selective course of <Innovative training on engineering> opened up in our center is dedicated for students who have completed the courses of metalworking practice and competence training on engineering practice. Students could raise an innovative theme and after have it assessed by assessment committee; a corresponding professional teacher could be assigned for them to give further guidance. Those innovative themes will be studied in engineering training center, by utilizing the devices or equipment in the center, they will get analyzed, designed, drawn, machined and assembled. The excellent works are selected and encouraged to participate competitions like "Challenging Cup", "Mechanical Innovation 
Competition”. For works which are novel, innovative, practical, we can declare the patent for innovation or practical for utility models. For works which boasts the in-depth academic meaning, we encourage to write research paper so as to broaden the scientific thinking and ability of students.

\section{Conclusion}

For most of students the experience on "metalworking practice" is still remembered by them after graduation. The reason behind is that it is a practical training course which are different with other courses. Since the establishment of the course and especially in recent years, many beneficial exploration and practices have been made in many colleges and universities and the remarkable achievement is made. There are still spaces for "metalworking practice" this excellent gilded signboard to be developed, improved and enriched so as to let its function to be fully played in teaching. At the same time, based on metalworking practice, we should look for other path. We should explore and expand other practical training courses actively. We should take improving comprehensive quality of students as basis, taking the cultivation of the innovative spirit and engineering practical ability of students as main task and let metalworking practice play the very important role on aspects like strengthening engineering practical ability, fostering and developing innovative mind and spirit of students etc.

\section{Acknowledgements}

This dissertation is supported by Higher Education Reform and Practice Program of Hebei Province Education Department (2015GJJG096), Higher Education Research Subject of Hebei Province Higher Education Institute (GJXH2015-210), and Twelfth Five-Year Plan of Shijiazhuang Tiedao University (D201402,C201405).

\section{References}

[1] Fu Shuigen, Heavy responsibility and long way in form of metalworking series of courses ,Metalworking research, 1999, (3) 4-7.

[2] Zhang Jianchao, Wang Jun, Wei Yaoyuan, The optimization and upgrade of metalworking practice to engineering training, China science information, 2012, (11)263.

[3] Gao Qi, Li Ying, Zhang Fei, The teaching reform on “metalworking practice” based on engineering ability training , Research and exploration on laboratory, 2015(1) 234-237.

[4] Gong Yuan, Mei Da. Reform and research on metalworking practice teaching system in engineering colleges and universities, China electric power education, 2013(1) 129-130.

[5] Li Junxia, Yao Yunfeng, Wang Huixia, Reform and research on teaching of metalworking practice in colleges and universities, China modern education equipment, 2015(5) 87-89.

[6] Duan Chengyan, Miao Shujie, Wang Baicheng, Research and exploration on metalworking practice based on model of training excellent engineers, Value engineering, 2012, 31(31) 229-230.

[7] Su Huanhuan, Research and application of TRIZ theory in metalworking practice teaching, Modern manufacturing technique and equipment,2015(3) 78-80.

[8] Zhang Jianchao, Wu Wenjiang, Gao Zhanfeng, Engineering training and innovative platform building based on training idea of “excellent engineer”, Education and teaching forum, 2015(48) 115-116. 